\title{
Multi-type Noise Removal in Lead Frame Image Using Enhanced Hybrid Median Filter
}

\author{
Muhammad Syafiq Alza Alias", Norazlin Ibrahim ${ }^{\#}$, Zalhan Mohd Zin ${ }^{\#}$ \\ ${ }^{\#}$ Industrial Automation Section, Universiti Kuala Lumpur Malaysia France Institute, Bangi, 43650, Malaysia \\ E-mail:msyafiq.alias@s.unikl.edu.my,norazlin@unikl.edu.my,zalhan@unikl.edu.my
}

\begin{abstract}
Image filtering technique plays a very important role in digital image processing. It is one of the major steps in image enhancement and restoration. This filtering technique can remove noise and preserve the details of the image for feature extraction processes. However, filtering process can still be considered as a huge challenge for image filtering technique. Common noises in the image such as Salt \& Pepper, Gaussian, Speckle, and Poisson Noise are still posing problems in filtering process where the quality and the originality of the images can be degraded and disturbed. Meanwhile, a single filtering technique is usually fit to deal with only certain specific noise. This paper presents an enhanced Hybrid Median Filter $\left(\mathrm{H}_{6} F\right)$ technique to improve image filtering process. The technique involves $3 \times 3$ sub-mask and determination of new pixel value from the median value of the three steps which are the median calculation of '+'-neighbours, median calculation of all sub-masks and selection of centre pixel value. The H6F technique has been computed on lead frame inspection system. The results have shown that the technique has been able to remove multi-type of noises efficiently and produce exceptionally low Mean-Square Error (MSE) while consuming the acceptable amount of execution time when compared to other filtering techniques.
\end{abstract}

Keywords — image filtering; hybrid median filter; multi-type noise

\section{INTRODUCTION}

Images in digital image processing are normally corrupted, and its quality is usually degraded by the undesired signal called noise. Noise can be described as a random signal, and the main source of this signal comes from light levels and sensor temperature [1]. Besides that, the presence of noise also come from environmental conditions that affect the imaging sensor, dust particles that exist in the scanner and the interference in transmission channel [2]. Noise exists in various types and characteristics. Common types of noise that have been studied in digital image processing are Salt and Pepper noise, Gaussian noise, Speckle noise and Poisson noise [3].

According to [4], noise can destroy most of the part of image information which can lead to image distortion and reduce the visual quality of the image [5]. Due to noise, the digital image also could lose essential information for human or machine to analyse. Failing to analyse image correctly might give a negative impact on us especially in a critical area such as medicine that deal with human life and in industrial production in which can endanger the end user of the product. To address these noise related problems in digital image processing, image filtering technique has generally been applied to restore the originality of the image.
This technique is important to improve the accuracy of image processing algorithm. There are many image filtering techniques that have been developed such as a median filter to remove Salt and Pepper noise [6], Gaussian filter to remove Gaussian noise [7] and others [8], [9].

Image processing techniques have been used and applied in industrial production for quite some time specifically in machine's Vision System (VS) to check the quality or condition of specific products. Among the products that require quality inspection is a lead frame (Fig. 1). The lead frame is a thin layer of metal frame inside a chip package that carries signal from the die to outside in which semiconductors are attached during the package assembly process. The quality of the lead frame is very important because if there is any tiny defect, it can seriously endanger the performance and reliability of the Integrated Circuit (IC) device. The small size of the design and the reflective surface of the lead frame are the big challenges that need to be overcome to obtain good and high-quality images. Normally, the image of lead frame taken during the inspection using VS contains various types of noise and image filtering techniques have been commonly applied to deal with these noises. However, even though these techniques have been able to remove the specific or single type of noise, they still face difficulties when dealing with the images that contain multi-types of noise. 


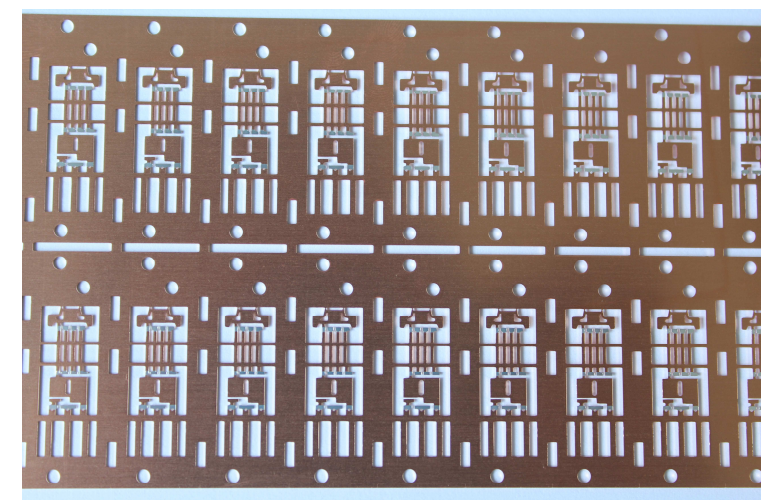

Fig. 1 A sample of lead frame image

Therefore, this research focuses on developing image filtering technique to remove multi-types of noise using an enhanced Hybrid Median Filter known as $\mathrm{H}_{6} \mathrm{~F}$ on lead frame image since there is a lack of study on lead frame images. This $\mathrm{H}_{6} \mathrm{~F}$ has been developed based on the widely-used Hybrid Median Filter (HMF) technique. The technique has been tested on lead frame inspection system and its performance was compared to other six image filtering techniques by using MSE method and execution time was taken. This research also focuses on the low-density type of noises since the vision system that use to inspect lead frame image is in a controlled condition that normally noises that present in the image is quite low. Basically, MSE method was used to investigate whether the filter used can remove noise or not. The execution time was taken to ensure the filter has a good quality of algorithm and determine whether it has acceptable time for the vision system to execute the program as mention in [1].

According to [2], the primary mechanism for image enhancement and restoration during the early development of image processing were the linear filters. This was due to their mathematical simplicity, simple design and easy implementation. However, the image that was processed using this linear filter tends to blur on the edges of the image and the filter did not remove Gaussian noise adequately. Many researches were conducted previously to improve image filtering methods. Non-linear filters were found to be the better filters in removing noise [3]. Among them are the common Median Filter (Med Filter), Minimum Filter (Min Filter) and Maximum Filter (Max Filter).

\section{A. Median Filter}

Firstly, as described in [4] and [5], Median Filter is a nonlinear filtering method that is known for its ability to remove impulsive type noise, while preserving sharp edges and fine details in digital images. In this filtering process, the value of the pixel at a certain point ' $p$ ' will be computed and replaced by the median value of its 8 -neighbourhood pixel. It can be defined as the following equation:

$$
g_{-} \operatorname{med}(p)=\operatorname{median}\left\{f(p), \text { where } p \in N_{8}(p)\right\}
$$

where $g \_\operatorname{med}(p)$ is the output of the Median Filter at image point $p$, median\{.\} is the median operator, $f(p)$ is the input image of point $p$ and $N_{8}$ is the 8-neighbourhood pixel of point $p$.

\section{B. Minimum Filter}

The second non-linear filter which is Min Filter will enhance the dark values of the pixel in the image by increasing its area. This method is similar to the dilate function that processes the darkest area in the surrounding pixel and extends the region. Min Filter will select the minimum value of the 8-neighbourhood pixels of pixel 'p' (darkest point) and replace it at the pixel 'p'. The output g_min(p) of Min Filter at image point $\mathrm{p}$ can be defined as:

$$
g_{-} \min (p)=\min \left\{f(p), \text { where } p \in N_{8}(p)\right\}
$$

where $g \_\min (p)$ is the output of the Min Filter at image point $p, \min \{$.$\} is the minimum operator, f(p)$ is the input image of point $p$ and $N_{8}$ is the 8-neighbourhood pixel of point $p$.

\section{Maximum Filter}

The third non-linear filter which is Max Filter acts as the opposite of Min Filter. Max Filter will select the maximum value of the 8-neighbourhood pixels of pixel 'p' (brightest point) and replace it at pixel ' $p$ '. The definition of Max Filter can be written as:

$$
g_{-} \max (p)=\max \left\{f(p), \text { where } p \in N_{8}(p)\right\}
$$

where $g_{-} \max (p)$ is the output of the Max Filter at image point $p, \max \{$.$\} is the maximum operator, f(p)$ is the input image of point $p$ and $N_{8}$ is the 8-neighbourhood pixel of point $p$.

In general, Max Filter is good for removal of Pepper noise type while Min Filter performs better in removing Salt noise type [6].

\section{Hybrid Median Filter (HMF)}

HMF [7] is a nonlinear filter that commonly used in image processing to remove impulsive noise. It can preserve the edges of an image better than the basic median filter. After this three-steps ranking operation technique is developed, it is widely used and improved ever since by others [8], [9] with the aim to remove noise better. HMF has a vital role in image processing and can be written as:

$$
\operatorname{hmf}(p)=\operatorname{median}\left\{\begin{array}{c}
\text { median }\left\{f(p), \text { where } p \in+_{5}(p)\right\} \\
\operatorname{median}\left\{f(p), \text { where } p \in x_{5}(p)\right\} \\
f(p)
\end{array}\right\}
$$

where $h m f(p)$ is the output of the HMF filter at image point $p$, median \{.\} is the median operator, $f(p)$ is the input image of point $p,+_{5}$ is the ' + ' neighbours of point $p$ and $x_{5}$ is the ' $\mathrm{x}$ ' neighbours of point $p$. If point ' $\mathrm{p}$ ' has $(\mathrm{x}, \mathrm{y})$ coordinate, then '+'-neighbours of point ' $\mathrm{p}$ ' are at coordinate $(\mathrm{x}-1, \mathrm{y}),(\mathrm{x}+1$, $y),(x, y-1)$ and $(x, y+1)$ while ' $x$ '-neighbours of point ' $p$ ' are at coordinate $(\mathrm{x}+1, \mathrm{y}+1),(\mathrm{x}+1, \mathrm{y}-1),(\mathrm{x}-1, \mathrm{y}+1)$ and $(\mathrm{x}-1, \mathrm{y}-$ 1). of point $p$.

In 2013, this hybrid technique was used to remove impulse noise and was tested on rice image as studied in [10]. As mentioned in this study, HMF can remove impulse noise smooth and efficiently. Besides that, it also preserves the edges and brightness difference better when compared to Median Filter. 


\section{E. Hybrid Cross Median Filter $\left(H_{l} F\right)$}

Hybridization of image filtering techniques has been introduced since more than two decades ago to improve image filtering processes. The Hybrid Cross Median Filter or $\mathrm{H}_{1} \mathrm{~F}$ has been considered as a non-linear filtering technique for image enhancement and was first introduced in 2011 to remove Gaussian noise from brain tumor image [7]. The results show that $\mathrm{H}_{1} \mathrm{~F}$ works better than $\mathrm{HMF}$ and Median filter in removing Gaussian noise with the performance is measured by Root Mean Square Error (RMSE) method and Peak Signal Noise Ratio (PSNR) method. $\mathrm{H}_{1} \mathrm{~F}$ can be expressed as the following:

$$
H_{1} F(p)=\text { median }\left\{\begin{array}{c}
\text { median }\left\{f(p), \text { where } p \in L_{3}(p)\right\} \\
\text { median }\left\{f(p), \text { where } p \in R_{3}(p)\right\} \\
f(p)
\end{array}\right\} \text { (5) }
$$

where $H_{l} F(p)$ is the output of the $\mathrm{H}_{1} \mathrm{~F}$ filter at image point $p$, median \{.\} is the median operator, $f(p)$ is the input image of point $p, L_{3}$ is the LT neighbours of point $p$ and $R_{3}$ is the RT neighbours of point $p$.

As defined in equation [4], $\mathrm{H}_{1} \mathrm{~F}$ works by determining the median ' $\mathrm{m}$ ' of the median value of the pixel of LT neighbours of point ' $p$ ', the median value of the pixel of RT neighbours of point ' $p$ ' and the pixel value of point ' $p$ '. This median ' $m$ ' is then replaced the pixel value of point ' $p$ '. If point ' $\mathrm{p}$ ' has $(\mathrm{x}, \mathrm{y})$ coordinate, then LT neighbours are at point $(\mathrm{x}-1, \mathrm{y}-1)$ and $(\mathrm{x}+1, \mathrm{y}+1)$ while $\mathrm{RT}$ neighbours are at point $(\mathrm{x}+1, \mathrm{y}-1)$ and $(\mathrm{x}-1, \mathrm{y}+1)$.

\section{F. Hybrid Min Filter $\left(\mathrm{H}_{2} \mathrm{~F}\right)$}

Hybrid Min Filter or $\mathrm{H}_{2} \mathrm{~F}$ is another hybrid image filtering technique, and it has played an important role in image processing and vision system. $\mathrm{H}_{2} \mathrm{~F}$ is different from Min Filter and has been used to remove Salt noise. This filter was proposed in the same paper that proposed $\mathrm{H}_{1} \mathrm{~F}$ and tested with medical image to remove Gaussian noise [7]. The $\mathrm{H}_{2} \mathrm{~F}$ will take the minimum of the median value of the pixel of LT neighbours of point 'p', the median value of the pixel of RT neighbours of point ' $p$ ' and the pixel value of point ' $p$ ' and then use it to replace the pixel value of point ' $\mathrm{p}$ '. $\mathrm{H}_{2} \mathrm{~F}$ can be defined as:

$$
H_{2} F(p)=\min \left\{\begin{array}{c}
\text { median }\left\{f(p), \text { where } p \in L_{3}(p)\right\} \\
\operatorname{median}\left\{f(p), \text { where } p \in R_{3}(p)\right\} \\
f(p)
\end{array}\right\}
$$

where $\mathrm{H}_{2} \mathrm{~F}(p)$ is the output of the $\mathrm{H}_{2} \mathrm{~F}$ filter at image point $p$, $\min \{$.$\} is the minimum operator, median \{$.$\} is the median$ operator, $f(p)$ is the input image of point $p, L_{3}$ is the LT neighbours of point $p$ and $R_{3}$ is the RT neighbours of point $p$.

\section{G. Hybrid Max Filter $\left(\mathrm{H}_{3} \mathrm{~F}\right)$}

The fourth hybrid technique is known as Hybrid Max Filter or $\mathrm{H}_{3} \mathrm{~F}$. It is different from usual Max Filter and suitable for Pepper noise. According to [7], $\mathrm{H}_{3} \mathrm{~F}$ can remove Gaussian noise from brain tumor image significantly better than $\mathrm{H}_{1} \mathrm{~F}$ and $\mathrm{H}_{2} \mathrm{~F} . \mathrm{H}_{3} \mathrm{~F}$ performs by taking the maximum of median value of the pixel of LT neighbours of point ' $p$ ', the median value of the pixel of RT neighbours of point ' $p$ ' and the median value of the pixel of point ' $p$ ' and then replace the pixel value of point ' $p$ '. This hybrid technique can be written as:

$$
H_{3} F(p)=\max \left\{\begin{array}{c}
\text { median }\left\{f(p), \text { where } p \in L_{3}(p)\right\} \\
\text { median }\left\{f(p), \text { where } p \in R_{3}(p)\right\} \\
f(p)
\end{array}\right\}
$$

where $H_{3} F(p)$ is the output of the $\mathrm{H}_{3} \mathrm{~F}$ filter at image point $p$, $\max \{$.$\} is the maximum operator, median\{.\} is the median$ operator, $f(p)$ is the input image of point $p, L_{3}$ is the LT neighbours of point $p$ and $R_{3}$ is the RT neighbours of point $p$.

\section{H. Hybrid Sigma Filter $\left(\mathrm{H}_{4} \mathrm{~F}\right)$}

Besides that, in 2013, the authors in [2] have proposed another hybrid technique called Hybrid Sigma Filter or $\mathrm{H}_{4} \mathrm{~F}$. $\mathrm{H}_{4} \mathrm{~F}$ will take the median of the median value of the pixel of sigma neighbours of point ' $p$ ', the median value of the pixel of all neighbours of point ' $p$ ' and value of the pixel of point ' $p$ ' and then use it to replace the pixel value of point ' $p$ '. This $\mathrm{H}_{4} \mathrm{~F}$ technique has been considered to work well for medical images. This $\mathrm{H}_{4} \mathrm{~F}$ can be written as:

$$
H_{4} F(p)=\operatorname{median}\left\{\begin{array}{c}
\text { median }\left\{f(p), \text { where } p \in N_{8}(p)\right\} \\
\text { median }\left\{f(p), \text { where } p \in \varepsilon_{5}(p)\right\} \\
f(p)
\end{array}\right\} \text { (8) }
$$

where $H_{4} F(p)$ is the output of the $\mathrm{H}_{4} \mathrm{~F}$ filter at image point $p$, median \{.\} is the median operator, $f(p)$ is the input image of point $p, \mathrm{~N}_{8}$ is the 8-neighbourhood pixel of point $p$ and $\varepsilon_{5}$ is the sigma neighbours of point $p$. If point ' $p$ ' has $(\mathrm{x}, \mathrm{y})$ coordinate, then sigma neighbours are at the point $(x-1, y)$, $(\mathrm{x}+1, \mathrm{y}),(\mathrm{x}, \mathrm{y}-1)$ and $(\mathrm{x}-1, \mathrm{y}-1)$.

\section{Hybrid Min Max Filter $\left(\mathrm{H}_{5} \mathrm{~F}\right)$}

The first introduction of Hybrid Min Max Filter or $\mathrm{H}_{5} \mathrm{~F}$ was in 2012. This $\mathrm{H}_{5} \mathrm{~F}$ is the hybridization of $\mathrm{H}_{2} \mathrm{~F}$ and $\mathrm{H}_{3} \mathrm{~F}$ to remove Salt and Pepper noises. It is presented through the work done in [11]. This technique was tested using knee image with various noise level. Through the investigation, $\mathrm{H}_{5} \mathrm{~F}$ has the best performance in removing random Impulse noise when compared with Fuzzy Hybrid Max Filter, Median Filter, Mean Filter, M3 Filter (hybridization of Mean and Median Filter), Enhanced Hybrid Median Filter and $\mathrm{H}_{3} \mathrm{~F}$. Basically, $\mathrm{H}_{5} \mathrm{~F}$ works by first applying $\mathrm{H}_{2} \mathrm{~F}$ and then $\mathrm{H}_{3} \mathrm{~F}$. It can be written as the following definitions:

$$
\begin{gathered}
g(p)=\min \left\{\begin{array}{c}
\text { median }\left\{f(p), \text { where } p \in L_{3}(p)\right\} \\
\text { median }\left\{f(p), \text { where } p \in R_{3}(p)\right\} \\
f(p)
\end{array}\right\} \\
H_{5} F(p)=\max \left\{\begin{array}{l}
\text { median }\left\{g(p), \text { where } p \in L_{3}(p)\right\} \\
\operatorname{median}\left\{g(p), \text { where } p \in R_{3}(p)\right\} \\
f(p)
\end{array}\right\}
\end{gathered}
$$

where $\mathrm{g}(p)$ is the output of the $\mathrm{H}_{2} \mathrm{~F}$ filter at image point $p$, $H_{5} F(p)$ is the output of the $\mathrm{H}_{5} \mathrm{~F}$ filter at image point $p$, $\max \{$. is the maximum operator, $\min \{$.$\} is the minimum operator,$ median \{.\} is the median operator, $f(p)$ is the input image of 
point $p, L_{3}$ is the LT neighbours of point $p$ and $R_{3}$ is the $\mathrm{RT}$ neighbours of point $p$.

In 2014 , this hybrid $\mathrm{H}_{5} \mathrm{~F}$ technique was tested on brain images for Gaussian noise removal, dog image for speckle noise removal and the Lena image for impulse noise removal with comparison with Wiener filter technique. It has been concluded in [12] that $\mathrm{H}_{5} \mathrm{~F}$ can independently remove Gaussian noise, Speckle noise and impulse noise in the respective images with significantly higher performance than Wiener filter. However, the images that contain multi-types of noises have neither been tested by this $\mathrm{H}_{5} \mathrm{~F}$ nor the previous hybrid techniques.

\section{MATERIAL AND METHOD}

In this research, an enhanced Hybrid Median Filter or $\mathrm{H}_{6} \mathrm{~F}$ has been proposed and tested. $\mathrm{H}_{6} \mathrm{~F}$ has been developed based on the modification of HMF. The proposed technique uses $3 \times 3$ sub-mask and the determination of new pixel value from the median value of the three following steps: a) median calculation of ' + ' neighbours of point ' $p$ '; b) median calculation of all sub-mask of point 'p' and c) selection of centre pixel value of point 'p'. Fig. 1 shows the process of $\mathrm{H}_{6} \mathrm{~F}$.

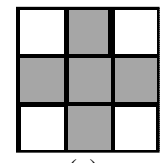

(a)

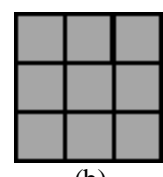

(b)

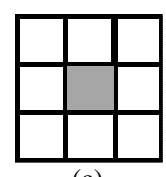

(c)
Fig. 2 Determination of $\mathrm{H}_{6} \mathrm{~F}$ pixel from the three steps: (a) median calculation of '+'-neighbours; (b) median calculation of all sub-mask; and (c) selection of centre pixel value

If point ' $p$ ' has $(x, y)$ coordinate, then ' + ' neighbours of point ' $\mathrm{p}$ ' are at coordinate $(\mathrm{x}-1, \mathrm{y}),(\mathrm{x}+1, \mathrm{y}),(\mathrm{x}, \mathrm{y}-1)$ and $(\mathrm{x}$, $y+1)$. All the sub-masks are at coordinate $(x+1, y+1),(x$, $\mathrm{y}+1),(\mathrm{x}-1, \mathrm{y}+1),(\mathrm{x}+1, \mathrm{y}),(\mathrm{x}, \mathrm{y}),(\mathrm{x}-1, \mathrm{y}),(\mathrm{x}+1, \mathrm{y}-1),(\mathrm{x}, \mathrm{y}-1)$ and $(\mathrm{x}-1, \mathrm{y}-1)$. Mathematically, $\mathrm{H}_{6} \mathrm{~F}$ can be written as:

$$
h_{6} f(p)=\text { median }\left\{\begin{array}{c}
\text { median }\left\{f(p), \text { where } p \in+_{5}(p)\right\} \\
\text { median }\left\{f(p), \text { where } p \in N_{8}(p)\right\} \\
f(p)
\end{array}\right\} \text { (10) }
$$

where $h_{6} f(p)$ is the output of the $\mathrm{H}_{6} \mathrm{~F}$ filter at image point $p$, median \{.\} is the median operator, $f(p)$ is the input image of point $p,{ }_{5}$ is the ' + '-neighbours of point $p$ and $N_{8}$ is the 8neighbourhood pixel of point $p$. The algorithm of $\mathrm{H}_{6} \mathrm{~F}$ technique can be defined as follows:

- Read the original image,

- Convert the original image from RGB to grayscale,

- Determine the 3x3 sub-mask with padded replicate,

- Find the median of '+'-neighbours,

- Find the median of all sub-masks,

- Select the centre pixel value,

- Calculate the median of value from step (4), (5) and (6),

- Replace the centre pixel value with the newly calculated value in step (7).

The performance of $\mathrm{H}_{6} \mathrm{~F}$ technique has been analysed and compared to other hybrid techniques by using Mean Square
Error (MSE) method. This MSE method basically represents the average difference between the original image and the predicted image [13]. MSE can be defined as:

$$
M S E=\frac{1}{M N} \sum_{j=1}^{M} \sum_{k=1}^{N}\left(X_{j . k}-X_{j . k}^{\prime}\right)^{2}
$$

where MSE is the output of MSE value, $X_{j, k}$ is the desired output image, $X_{j, k}$ is the predicted output image and $\mathrm{m}$ and $\mathrm{n}$ are the total number of pixels in the horizontal and the vertical dimensions of the image respectively.

The lower the value of MSE indicates better performance of the technique.

\section{RESULTS AND DISCUSSION}

The $\mathrm{H}_{6} \mathrm{~F}$ filtering technique has been tested on a sample of 20 lead frame images, and the average of MSE was taken. The performance of $\mathrm{H}_{6} \mathrm{~F}$ has been compared to the performances of other six hybrid filtering techniques of $\mathrm{HMF}, \mathrm{H}_{1} \mathrm{~F}, \mathrm{H}_{2} \mathrm{~F}, \mathrm{H}_{3} \mathrm{~F}, \mathrm{H}_{4} \mathrm{~F}$, and $\mathrm{H}_{5} \mathrm{~F}$. Five types of noises which are Salt and Pepper, Gaussian, Speckle, Poisson and Multi-types noise (the other four noises combined together) were added to the input images of all six filtering techniques. The execution time for each algorithm was also taken for comparison and analysis. All experiments have been conducted on MATLAB R2014a and computer used for simulations was an Intel Core i7-6700K CPU with $4.00 \mathrm{GHz}$ working frequency and 8G RAM.

Table 1 shows the average MSE value of all filters when Salt and Pepper noise with different densities were added into the 20 input images.

TABLE I

Average Value of MSE for 20 LEAd Frame IMAges Tested to

\begin{tabular}{|c|c|c|c|c|c|}
\hline \multirow[t]{2}{*}{ Filter } & \multicolumn{5}{|c|}{$\begin{array}{c}\text { MSE Value for Salt and Pepper Noise with } \\
\text { Different Density }\left(\mathrm{x10}^{4}\right)\end{array}$} \\
\hline & 0.02 & 0.04 & 0.06 & 0.08 & 0.10 \\
\hline HMF & 1.7239 & 2.4767 & 3.5636 & 4.3974 & 5.8098 \\
\hline $\mathrm{H}_{1} \mathrm{~F}$ & 3.0217 & 6.6056 & 11.8923 & 16.8483 & 23.9703 \\
\hline $\mathrm{H}_{2} \mathrm{~F}$ & 16.1565 & 30.0393 & 44.9280 & 58.2558 & 72.5367 \\
\hline $\mathrm{H}_{3} \mathrm{~F}$ & 11.9881 & 21.7785 & 33.3967 & 43.1139 & 53.9259 \\
\hline $\mathrm{H}_{4} \mathrm{~F}$ & 3.0245 & 3.5538 & 4.4541 & 5.1490 & 6.0320 \\
\hline $\mathrm{H}_{5} \mathrm{~F}$ & 6.9675 & 8.9170 & 11.8489 & 12.3597 & 16.6682 \\
\hline $\mathrm{H}_{6} \mathrm{~F}$ & 1.2777 & 1.5823 & 2.1725 & 2.6285 & 3.4207 \\
\hline
\end{tabular}
DiFFERENT DENSITIES OF SALT AND PEPPER NOISE

Based on Table 1, it can be concluded that the most successful image filtering technique in removing Salt and Pepper noise with different densities is $\mathrm{H}_{6} \mathrm{~F}$. The proposed technique has the lowest MSE value for each type of densities for Salt and Pepper noise which indicates that the technique has the low average difference between the original image and the filtered output image. Therefore, it can be said that this filter has recovered almost all part of the interrupted pixels in the image by the Salt and Pepper noise. The nearest filters that have as good performance as $\mathrm{H}_{6} \mathrm{~F}$ are $\mathrm{HMF}$ followed by $\mathrm{H}_{4} \mathrm{~F}, \mathrm{H}_{1} \mathrm{~F}$, and $\mathrm{H}_{5} \mathrm{~F}$. The $\mathrm{H}_{2} \mathrm{~F}$ and $\mathrm{H}_{3} \mathrm{~F}$ techniques performed poorly and the MSE values are more than 10 times higher compared to the $\mathrm{H}_{6} \mathrm{~F}$.

Next, the performance of all filters when Gaussian noise with different densities was added into the 20 lead frame 
images is investigated. The average MSE values calculated were presented in Table 2 .

TABLE II

AVERAgE VALUE of MSE for 20 LEAD Frame IMAGES TESTED to DIFFERENT DENSITIES OF GAUSSIAN NOISE

\begin{tabular}{|l|c|c|c|c|c|}
\hline \multirow{2}{*}{ Filter } & \multicolumn{6}{|c|}{ MSE Value for Gaussian Noise with Different } \\
& \multicolumn{5}{|c|}{ Density (x10 } \\
& $\mathbf{0 . 0 2}$ & $\mathbf{0 . 0 4}$ & $\mathbf{0 . 0 6}$ & $\mathbf{0 . 0 8}$ & $\mathbf{0 . 1 0}$ \\
\hline $\mathrm{HMF}$ & 1.3776 & 1.7703 & 2.4000 & 3.2696 & 4.4154 \\
\hline $\mathrm{H}_{1} \mathrm{~F}$ & 2.1492 & 2.5129 & 3.1116 & 3.9521 & 5.0121 \\
\hline $\mathrm{H}_{2} \mathrm{~F}$ & 2.3645 & 2.1011 & 2.1207 & 2.3999 & 2.9244 \\
\hline $\mathrm{H}_{3} \mathrm{~F}$ & 3.3458 & 4.2989 & 5.4206 & 6.7938 & 8.3960 \\
\hline $\mathrm{H}_{4} \mathrm{~F}$ & 1.2889 & 1.6556 & 2.2909 & 3.1580 & 4.3182 \\
\hline $\mathrm{H}_{5} \mathrm{~F}$ & 1.7168 & 1.7374 & 2.0377 & 2.5804 & 3.4034 \\
\hline $\mathrm{H}_{6} \mathrm{~F}$ & 1.0996 & 1.4782 & 2.1171 & 3.0051 & 4.1618 \\
\hline
\end{tabular}

According to Table 2, the results show that $\mathrm{HMF}, \mathrm{H}_{4} \mathrm{~F}$, $\mathrm{H}_{5} \mathrm{~F}$, and $\mathrm{H}_{6} \mathrm{~F}$ have quite identical performance while $\mathrm{H}_{1} \mathrm{~F}$, $\mathrm{H}_{2} \mathrm{~F}$, and $\mathrm{H}_{3} \mathrm{~F}$ have low performance in removing Gaussian noise. The proposed $\mathrm{H}_{6} \mathrm{~F}$ technique has the lowest MSE value for densities of 0.02 and 0.04. Meanwhile, for Gaussian noise with densities of $0.06,0.08$ and $0.10, \mathrm{H}_{5} \mathrm{~F}$ produced the lowest MSE value, and $\mathrm{H}_{6} \mathrm{~F}$ has the second lowest MSE value with a slightly different value compared to $\mathrm{H}_{5} \mathrm{~F}$.

The average value of MSE for 20 lead frame images tested with different densities of Speckle noise was calculated and presented in Table 3.

$$
\text { TABLE III }
$$

Average VAlue of MSE for 20 LEAD Frame IMAGEs TESTED to DIFFERENT DENSITIES OF SPECKLE-NOISE

\begin{tabular}{|c|c|c|c|c|c|}
\hline \multirow[t]{2}{*}{ Filter } & \multicolumn{5}{|c|}{$\begin{array}{l}\text { MSE Value for Speckle Noise with Different } \\
\text { Density }\left(\mathrm{x10}^{4}\right)\end{array}$} \\
\hline & 0.02 & 0.04 & 0.06 & 0.08 & 0.10 \\
\hline HMF & 11.7941 & 20.3009 & 28.1036 & 35.1146 & 42.0792 \\
\hline $\mathrm{H}_{1} \mathrm{~F}$ & 16.3148 & 29.3951 & 41. & 53 & 65.5970 \\
\hline $\mathrm{H}_{2} \mathrm{~F}$ & 22.3600 & 40.6160 & 58.2489 & 75.54 & 94.6686 \\
\hline $\mathrm{H}_{3} \mathrm{~F}$ & 18.1158 & 29.5966 & 39.6721 & 49.25 & 58.5291 \\
\hline $\mathrm{H}_{4} \mathrm{~F}$ & 11.7212 & 18.8937 & 25.1873 & 675 & 9953 \\
\hline $\mathrm{H}_{5} \mathrm{~F}$ & 19.3271 & 32.3048 & 44.2900 & 55.5255 & 68.2614 \\
\hline $\mathrm{H}_{6} \mathrm{~F}$ & 9.9348 & 17.1326 & 23.5186 & 29.2564 & 35.0315 \\
\hline
\end{tabular}

By referring to Table 3 , the filtering technique that removes speckle noise efficiently is $\mathrm{H}_{6} \mathrm{~F}$ technique. This technique had come up with the lowest MSE value compared to the other six filtering techniques. Besides that, $\mathrm{HMF}$ and $\mathrm{H}_{4} \mathrm{~F}$ also performed with quite a similar result while $\mathrm{H}_{1} \mathrm{~F}, \mathrm{H}_{2} \mathrm{~F}, \mathrm{H}_{3} \mathrm{~F}$, and $\mathrm{H}_{5} \mathrm{~F}$ performed poorly. The $\mathrm{H}_{2} \mathrm{~F}$ technique has the higher MSE value with almost double the $\mathrm{H}_{6} \mathrm{~F}$ 's MSE value. The average MSE values for execution of the filtering technique on Poisson noise for 20 lead frame images are shown in Table 4.

In Table 5, the best performance in removing multi-type of noise in the lead frame image is $\mathrm{H}_{6} \mathrm{~F}$. The proposed filtering technique has the lowest average MSE value. HMF, $\mathrm{H}_{4} \mathrm{~F}$, and $\mathrm{H}_{5} \mathrm{~F}$ also can be classified as good multi-type noise removal because the MSE value is almost same as $\mathrm{H}_{6} \mathrm{~F}$. Meanwhile, $\mathrm{H}_{1} \mathrm{~F}, \mathrm{H}_{2} \mathrm{~F}$, and $\mathrm{H}_{3} \mathrm{~F}$ perform appallingly with a high value of MSE.
TABLE IV

Average MSE VALUE For 20 LEAD Frame IMAgEs TESTED to PoISSON NOISE

\begin{tabular}{|l|c|}
\hline Filter & MSE Value for Poisson Noise $\left(\mathbf{x 1 0}{ }^{4}\right)$ \\
\hline $\mathrm{HMF}$ & 4.0027 \\
\hline $\mathrm{H}_{1} \mathrm{~F}$ & 5.6263 \\
\hline $\mathrm{H}_{2} \mathrm{~F}$ & 9.2556 \\
\hline $\mathrm{H}_{3} \mathrm{~F}$ & 8.0819 \\
\hline $\mathrm{H}_{4} \mathrm{~F}$ & 4.9510 \\
\hline $\mathrm{H}_{5} \mathrm{~F}$ & 8.8169 \\
\hline $\mathrm{H}_{6} \mathrm{~F}$ & 3.3432 \\
\hline
\end{tabular}

The lowest average MSE value in Table4 is $\mathrm{H}_{6} \mathrm{~F}$ followed by $\mathrm{HMF}, \mathrm{H}_{4} \mathrm{~F}, \mathrm{H}_{1} \mathrm{~F}, \mathrm{H}_{3} \mathrm{~F}, \mathrm{H}_{5} \mathrm{~F}$, and $\mathrm{H}_{2} \mathrm{~F}$ respectively. Therefore, $\mathrm{H}_{6} \mathrm{~F}$ can be categorized as a good filtering technique in removing Poisson noise compared to the others. The lowest performance in removing this noise is $\mathrm{H}_{2} \mathrm{~F}$ with MSE value more than double the $\mathrm{H}_{6} \mathrm{~F}$ 's MSE value. HMF that has the second lowest MSE value performs only slightly different with $\mathrm{H}_{6} \mathrm{~F}$ and has a quite similar MSE value with $\mathrm{H}_{4} \mathrm{~F}$.

The multi-type of noise with different density is then experimented, and the outcome of each filter are shown in Table 5.

TABLE V

Average Value of MSE For 20 LEAd Frame IMAges TeSted to DIFFERENT DENSITIES OF MULTI-TYPE NOISE

\begin{tabular}{|l|c|c|c|c|c|}
\hline \multirow{2}{*}{ Filter } & \multicolumn{6}{|c|}{ MSE Value for Multi-type Noise with Different } \\
& \multicolumn{5}{|c|}{ Density (x10 } \\
\cline { 2 - 6 } & $\mathbf{0 . 0 2}$ & $\mathbf{0 . 0 4}$ & $\mathbf{0 . 0 6}$ & $\mathbf{0 . 0 8}$ & \multicolumn{1}{c|}{$\mathbf{0 . 1 0}$} \\
\hline $\mathrm{HMF}$ & 2.2348 & 3.2841 & 4.5678 & 5.9531 & 7.7536 \\
\hline $\mathrm{H}_{1} \mathrm{~F}$ & 3.8647 & 5.7050 & 7.9105 & 10.1986 & 12.9972 \\
\hline $\mathrm{H}_{2} \mathrm{~F}$ & 5.2282 & 7.2271 & 9.2039 & 11.3535 & 13.6884 \\
\hline $\mathrm{H}_{3} \mathrm{~F}$ & 5.8614 & 8.8117 & 1.2154 & 15.3969 & 19.3294 \\
\hline $\mathrm{H}_{4} \mathrm{~F}$ & 2.0046 & 2.8587 & 3.8880 & 4.9869 & 6.4445 \\
\hline $\mathrm{H}_{5} \mathrm{~F}$ & 3.0908 & 4.0721 & 5.1840 & 6.3880 & 7.8451 \\
\hline $\mathrm{H}_{6} \mathrm{~F}$ & 1.7925 & 2.6779 & 3.7579 & 4.9213 & 6.4432 \\
\hline
\end{tabular}

On the other hand, the execution time of each filter algorithm was taken 20 times by using MATLAB function 'tic' and 'toc'. The average times for all filters were then calculated and presented in Table 6

TABLE VI

Average of Time TAKEN TO EXECUTE EACH FILTER

\begin{tabular}{|c|c|}
\hline Filter & Execution Time (s) \\
\hline $\mathrm{HMF}$ & 3.019784 \\
\hline $\mathrm{H}_{1} \mathrm{~F}$ & 2.990989 \\
\hline $\mathrm{H}_{2} \mathrm{~F}$ & 2.841072 \\
\hline $\mathrm{H}_{3} \mathrm{~F}$ & 2.847189 \\
\hline $\mathrm{H}_{4} \mathrm{~F}$ & 2.991438 \\
\hline $\mathrm{H}_{5} \mathrm{~F}$ & 3.504634 \\
\hline $\mathrm{H}_{6} \mathrm{~F}$ & 2.988173 \\
\hline
\end{tabular}

As referred in Table 6 all the filters take around 2.8 seconds to 3 seconds to complete their tasks. Only $\mathrm{H}_{5} \mathrm{~F}$ takes about 3.5 seconds to complete the algorithm due to it' $\mathrm{s}$ complex algorithm which consists of the combination of $\mathrm{H}_{2} \mathrm{~F}$ and $\mathrm{H}_{3} \mathrm{~F}$. The lowest execution time is $\mathrm{H}_{2} \mathrm{~F}$ which has a very slightly different with $\mathrm{H}_{3} \mathrm{~F}$. The other three techniques which are $\mathrm{H}_{6} \mathrm{~F}, \mathrm{H}_{1} \mathrm{~F}$, and $\mathrm{H}_{4} \mathrm{~F}$ have shown moderate results and share almost same execution time. But $\mathrm{H}_{6} \mathrm{~F}$ has a tiny 
different value of about 0.01 second which makes it a better filter algorithm than $\mathrm{H}_{4} \mathrm{~F}$.

The following figures represent the input image, examples of the image with noise and the output image after applying filtering technique.

Firstly, Fig. 3 shows the example of an original image of a lead frame that was taken by a camera and converted to a grayscale image and used as the input image.

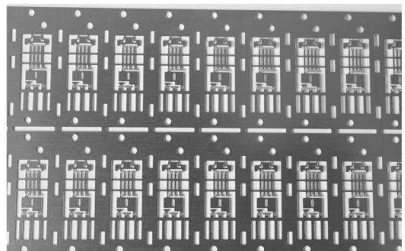

Fig. 3 A sample of grayscale lead frame image that is used as input image

In Fig. 4, black and white pixels can be seen scattered in the image. These black and white pixels that randomly appeared are known as Salt and Pepper noise with 0.10 density.

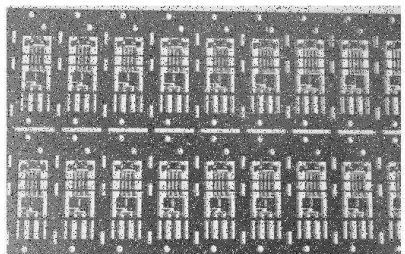

Fig. 4 An example of Salt and Pepper noise in image

Besides that, an example of Gaussian noise with a density of 0.10 in the image is shown in Fig. 5.

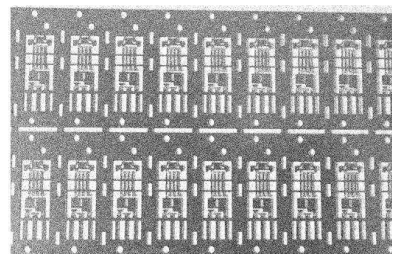

Fig. 5 Gaussian noise added to lead frame image

Next figure shows the example image with Speckle noise (Fig. 6).

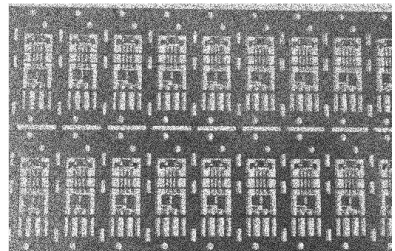

Fig. 6 A sample of Speckle noise in input image

In Fig. 7, Poisson noise is shown, and it is modelled by Poisson process.

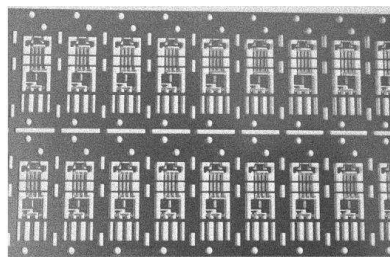

Fig. 7 A lead frame image with Poisson noise
Image with multi-type of noise which Salt and Pepper, Gaussian, Speckle and Poisson noise is added together is presented in Fig, 8.

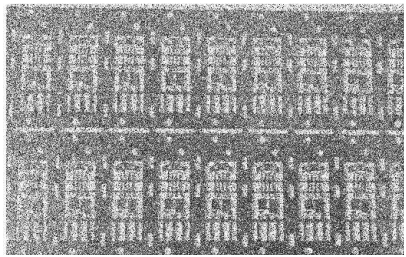

Fig. 8 Lead frame image with multi-type of noise

Based on human vision perspective, image filtered by $\mathrm{H}_{6} \mathrm{~F}$ technique (Fig. 9) has a better view and look almost same as the original image compared to $\mathrm{H}_{2} \mathrm{~F}$ technique (Fig. 10). This indicates that the $\mathrm{H}_{6} \mathrm{~F}$ can remove multi-type of noise efficiently and able to recover the original pixel quite well.
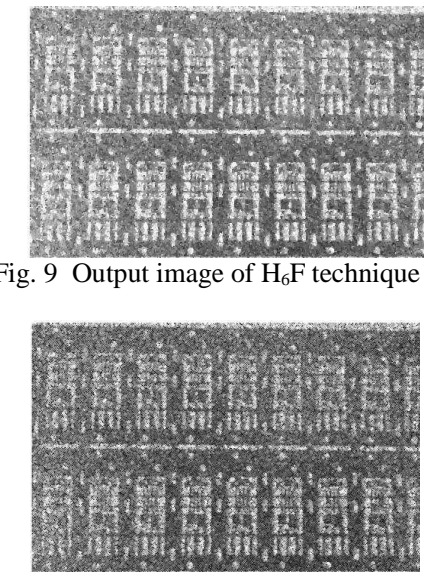

Fig. 10 Output image of $\mathrm{H}_{2} \mathrm{~F}$ technique

Filtering image with multi-type of noise is considered as a big challenge in image processing. This is due to its complicated attributes such as the probability of salt and pepper, Gaussian distribution and Poisson process that are added together to the image. This noise can affect the Vision System inspection. For example, in Fig. 8, it is very confusing for human or machine to determine the originality of the image. Therefore, $\mathrm{H}_{6} \mathrm{~F}$ is one of the good techniques to solve this issue. It is important to improve the image quality for visualization and analysis by eliminating the bad factors to recover the useful information from the degraded image as highlighted in [22], [23].

\section{IV.CONCLUSION}

This research has shown that $\mathrm{H}_{6} \mathrm{~F}$ is a better filtering technique in removing Salt and Pepper noise, Speckle noise, Poisson noise and multi-type of noise when compared to other filtering techniques. This technique also works well with Gaussing noise for the density of 0.02 and 0.04 . After conducting this $\mathrm{H}_{6} \mathrm{~F}$ in lead frame images, the results have shown that it has the lowest MSE values for almost all noises tested, which mean that the filter performs well in removing noises in images. The nearest ones that can challenge the performance of this filter are $\mathrm{HMF}$ and $\mathrm{H}_{4} \mathrm{~F}$. In the analysis of execution time, the results have also shown that $\mathrm{H}_{6} \mathrm{~F}$ had slightly lower and acceptable execution time which indicates that the algorithm of $\mathrm{H}_{6} \mathrm{~F}$ can be considered 
as having higher quality than $\mathrm{H}_{4} \mathrm{~F}$ 's algorithm and it can save more time. Although the lowest execution time is owned by $\mathrm{H}_{2} \mathrm{~F}$ and $\mathrm{H}_{3} \mathrm{~F}$ respectively, the accomplishment on removing noises in lead frame images are lower in both of them when compared to $\mathrm{H}_{6} \mathrm{~F}$ technique. Finally, with this performance achievement, it would be possible to apply $\mathrm{H}_{6} \mathrm{~F}$ in Vision System in order to improve the performance of quality inspection.

\section{ACKNOWLEDGMENT}

We would like to thank Universiti Kuala Lumpur Malaysia France Institute for the support and assistance under research grant of Universiti Kuala Lumpur ShortTerm Research Grant (STRG) Scheme STR15142.

\section{REFERENCES}

[1] Tania S, Rowaida R. A Comparative Study of Various Image Filtering Techniques for Removing Various Noisy Pixels in Aerial Image. Int J Signal Process Image Process Pattern Recognit [Internet]. 2016;9(3):113-24. Available from: http://dx.doi.org/10.14257/ijsip.2016.9.3.10\%5Cr

[2] Pandey A, Singh KK. Analysis of Noise Models in Digital Image Processing. Int J Sci Technol Manag. 2015;4(1):140-4

[3] Patidar P, Srivastava S. Image De-noising by Various Filters for Different Noise. Int J Comput Appl. 2010;9(4):45-50.

[4] Kumar Boyat A, Joshi BK. A Review Paper: Noise Models in Digital Image Processing. An Int J. 2015;6(2):63-75.

[5] Chandel R, Gupta G. Image Filtering Algorithms and Techniques: A Review. Int J Adv Res Comput Sci Softw Eng. 2013;3(10):2277128.

[6] Priestley JJ, Anusuya T, Pratheepa R, Elamaran V. Salt and Pepper Noise Reduction with a Novel Approach of Noise Models using Median Filter. In: IEEE International Conference on Computational Intelligence and Computing Research. 2014. p. 1-4.

[7] Kopparapu SK, Satish M. Identifying Optimal Gaussian Filter for Gaussian Noise Removal. Third Natl Conf Comput Vision, Pattern Recognition, Image Process Graph. 2011;(4):126-9.

[8] Kumar A, Datta A. Adaptive Edge Discriminated Median Filter To Remove Impulse Noise. Int Conf Comput Commun Autom. 2016;1409-13.
[9] Kumar SV. Hybrid Filters for Medical Image Reconstruction African J Math Comput Sci Res. 2013;6(9):177-82.

[10] Vahidi MR, Kashani MMR, Bagheri A. An Efficient Gradient based Algorithm for Improving Performance of Image Edge Detection. Int J Comput Appl. 2014;103(4):7-14.

[11] Joshi A, Boyat AK, Joshi BK. Impact of Wavelet Transform and Median Filtering on Removal of Salt and Pepper Noise in Digital Images. Int Conf Issues Challenges Intell Comput Tech. 2014;83843.

[12] Kirchner M, Fridrich J. On Detection of Median Filtering in Digital Images. Computer (Long Beach Calif) [Internet]. 2010;7541:754110754110-2. Available from: http://link.aip.org/link/PSISDG/v7541/i1/p754110/s1\&Agg=doi.

[13] Pushpavalli R, Sivarajde G. A Hybrid Filtering Technique for Random Valued Impulse Noise Elimination on Digital Images. ACEEE Int J Signal Image Process. 2013;4(3):9-16.

[14] Sharma S, Kumar EK. A Comparison of Salt and Pepper Noise Removal Filters. Int J Eng Sci Comput. 2016;6(8):2627-30.

[15] Ilango G, Marudhachalam R. New Hybrid Filtering Techniques for Removal of Gaussian Noise from Medical Images. ARPN J Eng Appl Sci. 2011;6(2):8-12.

[16] Vanithamani R, Umamaheswari G, Ezhilarasi M. Modified Hybrid Median Filter for Effective Speckle Reduction in Ultrasound Images. Recent Adv Networking, VLSI Signal Process.

[17] Mustafa ZA, Abrahim BA, Kadah YM. K11. Modified Hybrid Median Filter for Image Denoising. Natl Radio Sci Conf. 2012;70512.

[18] Rakesh MR, Ajeya B, Mohan AR. Hybrid Median Filter for Impulse Noise Removal of an Image in Image Restoration. Int J Adv Res Electr Electron Instrum Eng. 2013;2(10):5117-24.

[19] Marudhachalam R, Ilango G. A New Hybrid Filtering Technique for Removal of Impulse Noise from Digital Images. Int $\mathbf{J}$ Math. 2012;3(6):2354-9.

[20] Ilango G, Marudhachalam R. A HMMF Filter for Removal of Noise From Digital Images. 2014;0-4.

[21] Sivakumar R, Gayathri MK, Nedumaran D. Speckle Filtering Of Ultrasound B-Scan Images - A Comparative Study Between Spatial And Diffusion Filters. IEEE Conf Open Syst. 2010;(Icos):80-5.

[22] On CK, Yau TK, Alfred R, Teo J, Anthony P, Cheng W. Backpropagation Neural Ensemble for Localizing and Recognizing Non-Standardized Malaysia's Car Plates. Int J Adv Sci Eng Inf Technol. 2016;6(6):1112-9.

[23] Talib ML bin, Nasirudin MF, Abdullah SNHS. A Study of Atmospheric Particles Removal in A Low Visibility Outdoor Single Image. Int J Adv Sci Eng Inf Technol. 2016;6(6):1081-8. 